\section{Arthrogryposis Following Treatment of Maternal Tetanus with Muscle Relaxants}

\section{Case Report}

A 29-year-old woman was admitted to the University College Hospital of the West Indies, on 3 February 1966, nine days after an attempted instrumental abortion, suffering from severe generalized tetanus, with a continuing intrauterine pregnancy of from 10 to 12 weeks' duration. The disease ran a severe course, necessitating curarization and prolonged mechanical ventilation. The details of the drugs administered are summarized in the Table.

The patient was readmitted to the obstetrical unit on 6 September 1966, and the next day was delivered spontaneously of a living male infant, weighing $3.56 \mathrm{~kg}$., after a first stage labour of 5 hours 30 minutes, and a second stage labour of 20 minutes. At no time were there signs of fetal distress. The placenta and membranes were delivered intact; the placenta showed some calcification and a few small infarcts, but was of normal weight.

The infant was examined on 30 September. The posture and over-all appearance are shown in the Fig. Head circumference $36 \mathrm{~cm}$., crown heel length $48 \mathrm{~cm}$. A normally active male baby within the limits of the rigidities. Low forehead, small lower jaw, and short neck and lateral webbing. Right sternomastoid tumour. Bilateral gynaecomastia. Chest, heart, and lungs normal. Both flanks bulge paradoxically on straining, more so on the left. Left indirect inguinal hernia. No abnormality of the back.

Over-all limb proportions normal. The abnormal joints showed typical arthrogrypotic features, with flail movement over a given range, limited by solid, slightly springy blocks to further movement. Both scapulae high. Glenohumeral abduction to $70^{\circ}$, further scapular movement $20^{\circ}$. Flexed webbed elbows, extension to within $80^{\circ}$ of full range. Wrists and fingers held flexed, but normal ranges of joint movement against tight flexor muscles. Fingers normally developed. Thumbs held opposed and adducted across the palms.

Normal pelvis. Both hips irreducibly anteriorly dislocated, in $70^{\circ}$ external rotation and slight flexion, further flexion range $20^{\circ}$, other movements very limited. Stable knees held slightly flexed, no skin creases, extension to within $5^{\circ}$ of full range, flexion to $90^{\circ}$.

Severe talipes equinovarus, lateral skin dimples, forefoot and toes fully developed. Radiographs confirmed the dislocations of the hips. The number of cervical vertebrae was normal. The bone morphology was normal.

\section{Discussion}

This infant showed the deformities of arthrogryposis multiplex congenita, of the so-called, and more common, 'neurogenic' variety. Opinion is now hardening to the view that this condition is the end result of a number of pathological processes which immobilize the fetal limb at some period during, or shortly after, the formation of the joints (Drachman and Banker, 1961), and arthrogryposis has been produced in chicks by intravenous curarization in ovo for periods of 24-28 hours between the 7th and 15th day of incubation (Drachman and Coulombre, 1962). Necropsies in the 'neurogenic' cases have shown lesions in the central nervous system which all interrupt the final motor pathway, the most common being a selective depopulation of the anterior horn cells of the spinal cord and brain-stem, at levels appropriate to the muscles and joints affected. This is thought to be

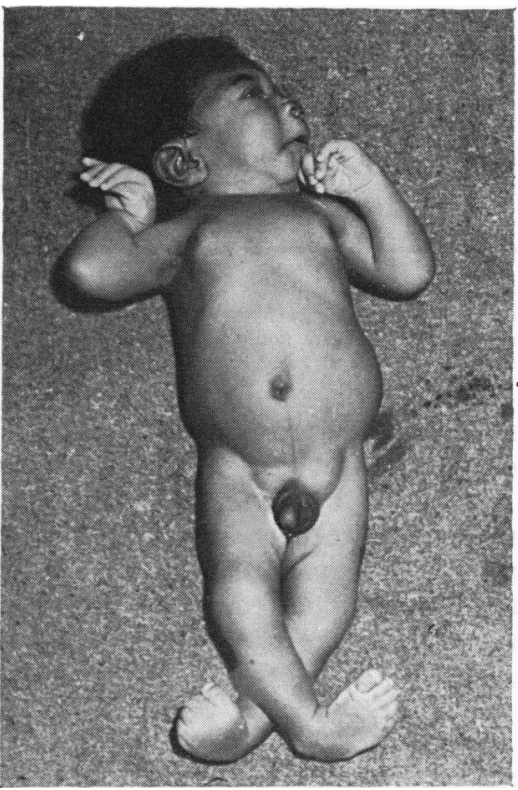

FIG.-Posture and appearance of infant. 
TABLE

Daily Total Doses of Drugs Administered to the Mother (mg.)

\begin{tabular}{|c|c|c|c|c|c|c|c|c|c|c|}
\hline $\begin{array}{l}\text { Day } \\
\text { No. }\end{array}$ & $\begin{array}{l}\text { d-Tubo- } \\
\text { curarine }\end{array}$ & Diazepam & $\begin{array}{l}\text { Chlor- } \\
\text { promazine }\end{array}$ & Digoxin & $\begin{array}{c}\text { Hydro- } \\
\text { chlorothiazide }\end{array}$ & $\begin{array}{c}\text { Anti- } \\
\text { biotics }\end{array}$ & $\begin{array}{l}\text { Seda- } \\
\text { tives } \ddagger\end{array}$ & Ventilation & Spasms & $\begin{array}{c}\text { Conscious } \\
\text { Level } \$\end{array}$ \\
\hline $\begin{array}{r}1 \\
2 \\
3 \\
4 \\
5 \\
6 \\
7 \\
\\
8 \\
\\
9 \\
10 \\
\\
11 \\
12 \\
13 \\
14 \\
15 \\
16 \\
17 \\
18 \\
19 \\
20 \\
21 \\
22 \\
23 \\
24 \\
25 \\
26 \\
27 \\
28 \\
29 \\
30 \\
31 \\
32 \\
33 \\
34 \\
35 \\
36\end{array}$ & $\begin{array}{c}125 \mathrm{iv} \\
60 \mathrm{im} \\
240 \mathrm{im} \\
210 \mathrm{im} \\
150 \mathrm{im} \\
90 \mathrm{im} \\
180 \mathrm{im} \\
15 \mathrm{iv} \\
90 \mathrm{im} \\
30 \mathrm{im} \\
1 \\
30 \mathrm{im} \\
60 \mathrm{im}\end{array}$ & $\begin{array}{l}40 \text { oral } \\
200 \text { oral } \\
240 \text { oral } \\
120 \text { oral } \\
20 \mathrm{im} \\
40 \mathrm{im} \\
\\
40 \mathrm{im} \\
10 \mathrm{iv} \\
10 \mathrm{im} \\
10 \mathrm{im} \\
40 \text { oral } \\
120 \text { oral } \\
160 \text { oral } \\
40 \mathrm{im} \\
120 \text { oral } \\
240 \text { oral } \\
240 \\
240 \\
200 \\
180 \\
120 \\
120 \\
120 \\
60 \\
60 \\
60 \\
60 \\
60 \\
60 \\
60 \\
60 \\
60 \\
50 \\
10 \mathrm{im} \\
50 \mathrm{oral} \\
10 \mathrm{im} \\
50 \mathrm{oral} \\
40 \mathrm{oral} \\
40\end{array}$ & $\begin{array}{l}100 \text { oral } \\
200 \text { oral } \\
\\
300 \\
200 \\
200 \\
200 \\
200 \\
200 \\
200 \\
200 \\
200 \\
200 \\
200 \\
200 \\
200 \\
100 \\
100 \\
50 \\
\\
50 \\
50\end{array}$ & 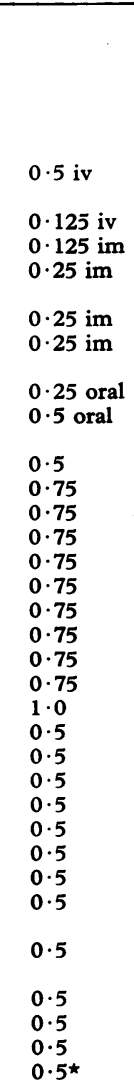 & $\begin{array}{l}100 \text { oral } \\
\\
100 \text { oral } \\
100 \\
100 \\
100 \\
100 \\
100 \\
100\end{array}$ & $\begin{array}{l}\text { a } \\
\text { a } \\
a \\
a \\
a \\
a \\
\text { b } \\
\text { b } \\
\text { b } \\
\text { b } \\
\text { c } \\
\text { c } \\
\text { c } \\
\text { c } \\
\text { c } \\
\text { c } \\
\text { c } \\
\text { c } \\
\text { c } \\
\text { c }\end{array}$ & $\begin{array}{l}\mathbf{z} \\
\mathbf{z} \\
\mathbf{z}^{\prime}\end{array}$ & 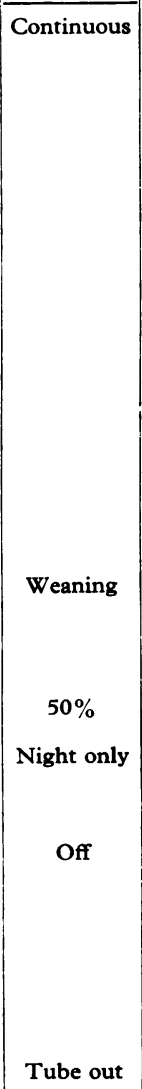 & $\begin{array}{c}\text { Numerous } \\
\text { Numerous } \\
\text { Moderate } \\
\text { Moderate } \\
\text { Moderate } \\
\text { Moderate } \\
\text { Moderate } \\
\text { Few } \\
\text { Nil } \\
\text { Few } \\
\text { Few } \\
\text { Few } \\
\text { Few } \\
\text { Few } \\
\text { Few } \\
\text { Few } \\
\text { Few } \\
\text { Few } \\
\text { Few } \\
\text { Nil } \\
\text { Nil } \\
\text { Nil } \\
\text { Nil } \\
\text { Nil } \\
\end{array}$ & $\begin{array}{l}5 \\
5 \\
5 \\
\\
2\end{array}$ \\
\hline
\end{tabular}

^Discontinued 13 March.

ta, crystalline penicillin 4 megas; b, a + streptomycin $1 \mathrm{~g}$; ; , tetracycline $1 \mathrm{~g}$.

$\ddagger z$, sodium amytal $750 \mathrm{mg}$; $\mathrm{z}^{\prime}$ sodium amytal $250 \mathrm{mg}$; $y$, chloral hydrate grains 30 .

$\$ 1$, fully conscious; 2 , sleeping but rouses to answer questions; 3 , responds to simple commands; 4 , responds to stimulation; 5 , unconscious

due to a degenerative process which begins after the formation of the nervous tissue, but which has largely burnt out by term. Muscle biopsies in surviving cases have been interpreted as showing the changes of denervation atrophy. This form of the disease is not inherited, and is associated with no retrospectively recognizable disease in the mother.

This same degenerative process, though rare, may have occurred in this fetus unconnected with the events of the pregnancy, and would be distinguished in a muscle biopsy at future surgery. In this case, however, there are other possible causes.
Maternal insults. The mother suffered severab episodes of severe hypoxia during the course of her illness, as well as bronchopneumonia and myo carditis.

Tetanus toxin. The principal tetanus toxin is a protein of a molecular weight of about 72,000 whose main action is to reduce the likelihood of the release of transmitter substance (which is probablye acetylcholine) on the arrival of the spike impulse at the endings of the inhibitory neurones acting in the motor pool of the spinal cord. A similar $\vec{\Phi}$ though clinically less apparent, effect has beenti 
demonstrated at myoneural junctions. Though proteins of this size can be transmitted to the fetus intact, the process is usually selective. However, absorption of tenanus toxin by the fetus from the uterine lumen has been shown in some species, and direct infection of the fetus, though almost certainly incompatible with fetal survival, cannot be entirely excluded. Nevertheless, it is unlikely that a toxin of this physiological specificity, even if it reached the fetus, would have any effects additional to those seen in the adult. There are several published reports of pregnancies surviving maternal tetanus in one of which the tetanus occurred at the end of the first trimester and in no case did an abnormal fetus result.

Drug-induced paralysis. The evanescence of effect of a single dose of d-tubocurarine depends on the diffusion of the drug away from the end-plate and its redistribution throughout the extracellular space, from which it is slowly removed. Repeated administration of the drug may saturate this space, and the duration of action come to depend on the rate of its excretion and destruction. Furthermore, in these circumstances, considerable fetal accumulation of the drug is to be expected, whereupon the same factors prolonging paralysis would operate.

This view is confirmed by a recent case report (Older and Harris, 1968), in which a mother, under treatment for status epilepticus with curarization and controlled ventilation, was delivered of a 28week fetus which was heavily curarized. In the current case the mother required continuous ventilation for 19 days, and it is probable that the fetus was paralysed for a comparable period, due to the action of d-tubocurarine, supplemented by diazepam and chlorpromazine.

\section{Conclusions}

While there are several possible causes for this infant's arthrogryposis, drug-induced immobilization of the fetus at the time of or shortly after the development of the joint cavities seems the most probable.

The severity of the deformities of this infant, and ubiquity of the drugs that may have caused them, would probably justify a review of the prolonged administration of relaxant drugs to women in the first trimester of pregnancy.

\section{Summary}

An infant with arthrogryposis was born to a mother who had been treated with d-tubocurarine in early pregnancy. The arthrogryposis is attributed to immobilization of the fetus at the time of joint formation.

I thank Mr. Mercer Rang for his constant interest and advice in the preparation of this paper, and for his permission to publish the case of the infant, who was under his care; Dr. C. G. Burgess of Roche Productions Ltd., for making available translations of Eastern European references, and for his advice concerning Valium.

\section{REFRRENCES}

Drachman, D. B., and Banker, B. Q. (1961). Arthrogrypossi multiplex congenita. Archives of Neurology, 5, 77.

_, and Coulombre, A. J. (1962). Experimental clubfoot and arthrogryposis multiplex congenita. Lancet, 2, 523.

Older, P. O., and Harris, J. M. (1968). Placental transfer of tubocurarine. British fournal of Anasthesia, 40, 459.

\section{R. H. JAGO*}

St. George's Hospital, Tooting Grove, London S.W.17

^Formerly Registrar, Department of Orthopaedic Surgery, University College Hospital of the West Indies, Mona, St. Andrew, Jamaica.

\section{Dermatitis Herpetiformis in a Treated Coeliac Child}

The relation between dermatitis herpetiformis (DH), structural and functional abnormalities of the small intestine, and coeliac disease with gluten sensitivity remains uncertain. It is well established that $\mathrm{DH}$ may be accompanied by malabsorption, and that such cases have abnormalities of the small intestinal villi of variable degree (Marks, Shuster, and Watson, 1966; Fraser, Murray, and Alexander, 1967; Fry et al., 1967; van Tongeren, van der Staak, and Schillings, 1967; Marks et al., 1968). Furthermore, malabsorption may precede the characteristic eruption of $\mathrm{DH}$ by several years (Fraser, Ferguson, and Murray, 1968). The importance or even relevance of these observations to gluten sensitivity is less clear, since the degree of villous atrophy found in DH may fall far short of subtotal villous atrophy which is the diagnostic essential in gluten sensitive coeliac disease. Nevertheless, gluten withdrawal may benefit the malabsorption syndrome of DH (van Tongeren et al., 1967; Marks et al., 1968; Fraser et al., 1968), and gluten sensitivity has been demonstrated in the small intestinal mucosa (Shuster, Watson, and Marks, 1968). In addition, improvement in the skin manifestations of $\mathrm{DH}$ has been noted in some patients on a glutenfree diet (van Tongeren et al., 1967; Marks et al., 